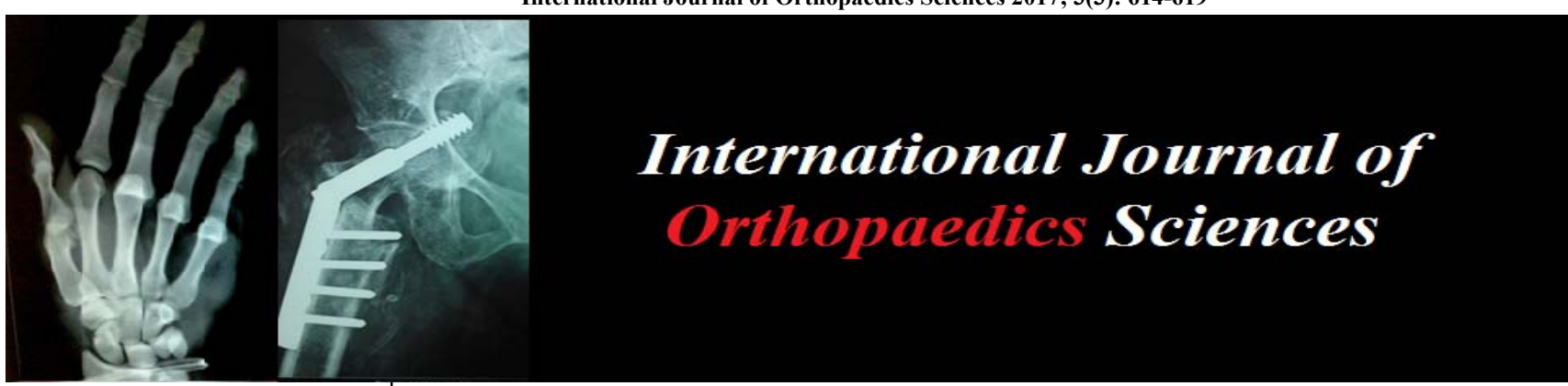

ISSN: 2395-1958

IJOS 2017; 3(3): 614-619

(C) 2017 IJOS

www.orthopaper.com

Received: 18-05-2017

Accepted: 20-06-2017

Dr. Jagadeesh Babu Somesula MS (Orthopaedics), Assistant Professor, Dept. of Orthopaedics, RVM Institute of Medical Sciences and Research Centre, Laxmakkapalli (v), Mulugu (M), Siddipet Dist, Telangana. India

Dr. Malleswara Rao Perumalla Venkata Naga

MS (Orthopaedics), Associate Professor, Dept. of Orthopaedics, NRI Institute of Medical Sciences, Sangivalasa, Visakhapatnam. Andhra Pradesh, India
Correspondence

Dr. Malleswara Rao Perumalla Venkata Naga

MS (Orthopaedics), Associate

Professor, Dept. of Orthopaedics,

NRI Institute of Medical

Sciences, Sangivalasa,

Visakhapatnam. Andhra

Pradesh, India

\section{A clinical study of various management techniques in distal end radius fractures in adults}

\author{
Dr. Jagadeesh Babu Somesula and Dr. Malleswara Rao Perumalla \\ Venkata Naga
}

DOI: http://dx.doi.org/10.22271/ortho.2017.v3.i3i.97

Abstract

Objectives: The present study was conducted to evaluate the functional outcome of distal radial fractures in adults with surgical treatment using closed reduction and K-wire fixation, external fixation with or without K-wire augmentation and assess the complications of various surgical procedures done for distal radial fractures.

Material and Methods: A prospective study was carried out on 20 adult patients with distal radial fractures. The fracture fragments were analysed and involvement of radio-carpal and distal radio-ulnar joints were assessed and classified according to the Frykman's classification

Regular follow up was done at an interval of 6 weeks, 3, 6 and 12 months. The follow up ranged from 5 to 12 months. The results were assessed at 3 months after the procedures.

Results: The functional outcome evaluated using the demerit score system of Gartland and Werley based on objective and subjective criteria and residual deformity, we achieved excellent results in 4 (20\%) cases, good results in 12 (60\%) cases, fair results in $3(15 \%)$ cases and poor result in 1 (5\%) case.

Conclusion: Surgical management of distal radial fractures, regardless of the type of fixation, produced excellent to good results with proper pre-operative evaluation, selection of the method based on fracture pattern, reducibility, stability and quality of bone, early fixation, proper wound and pin site care, early post-operative rehabilitation and patient education. Mal-union should be avoided by proper selection of implant and procedure, early reduction and fixation, better surgical skills.

Keywords: Distal end radius fractures, closed reduction, external fixation, radio carpal, radio ulnar joints

\section{Introduction}

Fractures of the distal end radius constitute one of the most common skeletal injuries treated by orthopaedic surgeons, accounting for $14 \%$ of fractures of the extremities and $17 \%$ of all skeletal fractures evaluated in emergency rooms ${ }^{[1,2]}$.

Distal radius fractures were often considered primarily stable extra articular fractures in the elderly. However, increasing experience has revealed that a vast majority of these fractures are articular injuries that disrupt both the radio carpal and distal radio ulnar joints. The articular injuries are more frequently comminuted and unstable, and therefore less suitable for more traditional methods of closed reduction and cast immobilization.

The optimal method of obtaining and maintaining an accurate restoration of distal radial anatomy remains a topic of considerable controversy and there is no single definitive treatment method that is considered the standard of care.

Several treatment methods including pins and plaster technique, closed reduction and percutaneous pinning, intra-focal pinning (Kapanji’s method), closed reduction and external fixation, limited open reduction, and open reduction and internal fixation with or without bone grafting are available. Augmentation of the external fixation using percutaneous Kirschner (K) wires and arthroscopically assisted reduction of intra articular fractures have also been shown to be useful.

In spite of various new advances, close reduction and cast immobilization has been the mainstay of treatment of these fractures but mal-union of fracture and subluxation / dislocation of distal radio-ulnar joint resulting in poor functional and cosmetic results is the usual outcome [3]. 
The purpose of the present study was to evaluate the functional outcome of distal radial fractures in adults with surgical treatment using various methods such as closed reduction and K-wire fixation, external fixation with or without K-wire augmentation.

Therefore, this study was aimed to identify different types of fractures of distal radius, study the functional outcome of distal radial fractures in adults treated surgically by using various methods and assess the complications of various surgical procedures done for distal radial fractures.

\section{Material and Methods}

A prospective study was conducted on 20 adult patients with distal radial fractures in the Department of Orthopaedics, Prathima Institute of Medical Sciences, Karimnagar, Telangana, India who attended the outpatient or the emergency service of Prathima Institute of Medical Sciences, Karimnagar, between October 2012 to September 2014. Patients were informed about the study in all aspects and informed consent was taken about their inclusion in the study. Ethical Committee approval was taken from the College Ethical Committee Board.

Inclusion criteria comprised of adult patients with distal radial fractures, patients willing to participate, exclusion criteria included elderly patients, patient with neurovascular deficiency, patient medically unfit for surgery, patient with pathological fractures.

Following admission to the hospital, a careful history was elicited from the patients and / or attendants to reveal the mode of injury and severity of trauma. Their general condition associated systemic diseases and associated injuries were noted and the findings were duly recorded in the patient proforma. Careful inspection of the deformity, swelling and ecchymosis were done. Clinically tenderness, bony irregularity, crepitus and the relative position of radial and ulnar styloid process were elicited. Movements of the wrist and forearm were checked and found to be painful and limited. Distal vascularity was assessed by radial artery pulsations, capillary fillings, pallor and paraesthesia over finger tips. The involved forearm was immobilized in a below elbow POP slab and kept elevated. Pain and inflammation were managed using analgesics like Diclofenac Sodium 50mg twice daily.

Routine examination of blood was done for haemoglobin percentage, total and differential WBC counts, fasting blood sugar, blood urea, serum creatinine, bleeding and clotting time, and HIV and HbsAg. Examination of urine was done for presence of albumin and sugar, blood pressure and ECG were recorded in all patients. Tetanus toxoid injection and intravenous antibiotic was given to all patients preoperatively. Physician fitness was obtained for all patients. Patients were operated after a pre-anaesthetic checkup.

Standard radiographs in PA and lateral views were taken for confirmation of the diagnosis and also to know the type of fracture. Oblique views were also taken in a few patients who had complex comminuted fractures. The fracture fragments were analysed and involvement of radio-carpal and distal radio-ulnar joints were assessed and classified according to the Frykman's classification.

The duration from the date of injury to date of operation ranged from 2-10 days. The choice of a particular procedure for each case depended on the fracture pattern, reducibility and stability and quality of bone. Closed reduction and external fixation was done for comminuted, unstable and impacted fractures. Distal radius fractures with metaphysal instability or simple intra articular displaced fractures treated with percutaneous pinning. In the cases which had a displaced radial styloid or fragments too small for other means of fixation, external fixation was augmented with Kirschner wires, inserted either percutaneously or through limited dorsal approach. The operations were performed under general anaesthesia in 18 cases and brachial block in 2 cases. The patients were followed up for two years

Instruments and implants used: The static external fixator used were Schanz screws, Aesculup clamps, 4mm connecting rods Kirschner wires of varying sizes. Percutaneous K- wire augmentation was done in selected cases by inserting the Kwires through the radial styloid process under fluoroscopic guidance. The fingers were left free to go through a full range of motion. No cast or splint was given.

After sterile preparation and draping, fracture was reduced by traction and the reduction was fluoroscopically evaluated. A $1.5 \mathrm{~cm}$ incision was given longitudinally, beginning at the radial styloid and proceeds distally across to the medial metaphysis and diaphysis at least two pins (1.6mm Kirschner wire) were inserted and confirmed adequate reduction on AP / LAT views. Another $1.6 \mathrm{~mm}$ K-wire was inserted percutaneously $90^{\circ}$ orthogonally to these wire, starting at the dorsal rim of distal radius just distal to the lister tubercle.

The correct starting point was confirmed with fluoroscopy and wire was driven in a proximal and volar direction across the fracture. Additional wires were placed as necessary to secure additional fracture fragments. The wires were bent and cut leaving them superficial to the skin.

The radial styloid incision was closed with interrupted absorbable sutures. A below elbow POP slab was applied. This splint was worn for 2 weeks then a soft arm cast was applied. The cast and pins were removed between 5 to 6 weeks usually.

Post-operative pain and inflammation were managed using anti-inflammatory analgesics. Vitamin-C tablets were given to avoid NSD. All patients were given intravenous Ceftriaxone $1 \mathrm{gm}$ twice daily and intramuscular Gentamicin 80mg twice daily for 5days. Affected limb was kept elevated and patients were asked to perform active finger movements from day one. Dressings were changed on the 5th post-operative day. Immediate post-operative check X-rays were taken in both PA and lateral views. The reduction of the fracture was confirmed and any displacements were noted. For patients treated with external fixator, the pin sites were cleaned with spirit on alternate days for further 5 days. Patients were discharged after the 10th post-operative day and advised active exercises. On follow-up at 6th week, the fracture union was assessed clinically by absence of tenderness and radiologically by bridging callus formation. Then the external fixator and Kwires, if any, were removed without general anesthesia on outpatient basis. The patients were advised not to lift heavy weights for further 4 to 6 weeks. In non-compliant patients, the splints were continued till the $1^{\text {st }}$ or $2^{\text {nd }}$ follow up.

After discharge, all patients were reviewed weekly for the first 6 weeks. Patients were assessed subjectively for pain at the fracture site, clinically for tenderness, loosening of the pins (external fixator cases) and any signs of infection. Pronation and supination of the forearm and active movement of the elbow and shoulder were advised throughout the period of healing. After the 6th week, physiotherapy was started, which included flexion-extension along with underwater exercises. The range of wrist movements was recorded and any deformity was assessed.

Check X-rays were taken at 6 weeks to assess consolidation 
or collapse at the fracture site and to note any displacement. The fracture was considered united when clinically there was no tenderness, subjective complaints, and radiologically when the fracture line was not visible. Fractures, which healed by 4 6 months, without an additional operative procedure were considered as delayed union. Fractures, which did not unite after 6 months, or those that needed additional operative procedure to unite was considered as non-union. Arthritic changes were graded according to the system described by Knirk and Jupiter ${ }^{[4]}$.

Regular follow up was done at an interval of 6 weeks, 3, 6 and 12 months. The follow up ranged from 5 to 24 months. The results were assessed at 3 months after the procedures using the demerit point system of Gartland and Werley ${ }^{[5]}$ based on objective and subjective criteria, residual deformity and complications (Table 3) and functional outcome of the results graded.

The objective evaluation is based on the following ranges of motion as being the minimum for normal function: dorsiflexion $45^{\circ}$, palmar flexion $30^{\circ}$, radial deviation $15^{\circ}$, pronation, $50^{\circ}$ and supination $50^{\circ}$.

\section{Statistical analysis}

The data was analyzed using simple statistical analysis for percentage calculation. Microsoft office (Word and Excel) professional 2007 software has been used to generate graphs and tables.

\section{Results}

The present study of 20 cases of distal radial fractures was conducted in the Department of Orthopaedics, Prathima Institute of Medical Sciences, Karimnagar, Telangana, India, from October 2012 to September 2014 and treated at Prathima Institute of Medical Sciences, Karimnagar, Telangana.

Table 1: Age incidence

\begin{tabular}{|c|c|c|c|c|}
\hline Age in years $\rightarrow$ & $\mathbf{2 1 - 3 0}$ & $\mathbf{3 1 - 4 0}$ & $\mathbf{4 1 - 5 0}$ & $\mathbf{5 1 - 6 0}$ \\
\hline No. of cases & 4 & 8 & 4 & 4 \\
\hline Percentage (\%) & 20 & 40 & 20 & 20 \\
\hline
\end{tabular}

In this series, 4 (20\%) patients were between 21 - 30 years, 8 (40\%) patients between 31 - 40 years, 4 (20\%) patients between 41 - 50 years, 4 (20\%) patients between 51 - 60 years (Table 1). The age of the patients ranged from 22 - 53 years with an average age 40.66 years.

Table 2: Distribution of cases according to sex incidence, side involvement, mode of injury

\begin{tabular}{|c|c|c|c|c|c|c|}
\hline \multirow{2}{*}{ Cases } & \multicolumn{2}{|c|}{ Sex incidence } & \multicolumn{2}{c|}{$\begin{array}{c}\text { Side } \\
\text { involvement }\end{array}$} & \multicolumn{2}{c|}{$\begin{array}{c}\text { Mode of } \\
\text { injury }\end{array}$} \\
\cline { 2 - 7 } & Male & Female & Right & Left & RTA & FOOH \\
\hline No. of cases & 16 & 4 & 16 & 4 & 14 & 6 \\
\hline $\begin{array}{c}\text { Percentage } \\
\text { (\%) }\end{array}$ & 80 & 20 & 80 & 20 & 70 & 30 \\
\hline
\end{tabular}

\section{RTA- Road traffic accident; FOOH- Fall on outstretched} hand

In this study, out of 20 cases 16 (80\%) were males and 4 (20\%) females, showing male predominance with the ratio 4 : 1 (M : F) (Table 2). Right side (dominant wrist) was involved in $16(80 \%)$ patients and the left side was involved in 4 (20\%) in our study (Table 2).

Mode of injury in majority of cases was road traffic accident (RTA). Of 20 cases, injury occurred due to road traffic accident in 14 (70\%) patients and fall on the out stretched hand in 6 (30\%) patients (Table 2).

Table 3: Type of fracture according to Frykman’s Classification

\begin{tabular}{|c|c|c|c|c|c|c|c|c|}
\hline $\begin{array}{c}\text { Type of } \\
\text { fracture } \rightarrow\end{array}$ & I & II & III & IV & V & VI & VII & VIII \\
\hline No. of cases & 0 & 0 & 4 & 0 & 2 & 2 & 12 & 0 \\
\hline $\begin{array}{c}\text { Percentage } \\
(\%)\end{array}$ & 0 & 0 & 20 & 0 & 10 & 10 & 60 & 0 \\
\hline
\end{tabular}

Out of 20 cases, 4 (20\%) cases were of Frykman's Type III, 2 (10\%) of Type V, 2 (10\%) of Type VI and 12 (60\%) cases of Type VII. There were no cases of Type I, II, IV and VIII fracture (Table 3).

Table 4: Associated injuries

\begin{tabular}{|c|c|c|c|c|c|}
\hline Associated Injuries $\rightarrow$ & Tibia shaft Fractures & Fracture shaft femur & Trochanteric fracture & Clavicle fracture & Total \\
\hline No. of cases & 2 & 1 & 3 & 0 & 6 \\
\hline Percentage (\%) & 10 & 5 & 15 & 0 & 30 \\
\hline
\end{tabular}

6 (30\%) patients had associated injuries which included tibia shaft, femur shaft and trochanteric fractures. None of the patients had clavicle, median nerve involvement or tendon injuries (Table 4).

Table 5: Duration of operation from date of injury and duration of fracture union

\begin{tabular}{|c|c|c|c|c|}
\hline \multirow{2}{*}{} & \multicolumn{2}{|c|}{ Duration } & \multicolumn{2}{c|}{ Time of Union } \\
\cline { 2 - 5 } & $\begin{array}{c}\mathbf{3 - 6} \\
\text { Days }\end{array}$ & 10 Days & $\begin{array}{c}\mathbf{2 - 3} \\
\text { months }\end{array}$ & $\begin{array}{c}\mathbf{3 - 4} \\
\text { months }\end{array}$ \\
\hline No. of cases & 19 & 1 & 12 & 8 \\
\hline $\begin{array}{c}\text { Percentage } \\
(\%)\end{array}$ & 1 & 5 & 60 & 40 \\
\hline
\end{tabular}

Surgery was done between 3 - 6 days in 19 (95\%) patients as an elective procedure. Surgery was delayed up to 10th day in 1 (5\%) patient who had hypertension and diabetes (Table 5).
Table 6: Type of fixation

\begin{tabular}{|c|c|c|}
\hline Type of fixation & $\begin{array}{c}\text { No. of } \\
\text { cases }\end{array}$ & $\begin{array}{c}\text { Percentage } \\
\text { (\%) }\end{array}$ \\
\hline Closed Reduction and K-Wire fixation & 15 & 75 \\
\hline $\begin{array}{c}\text { Closed Reduction, External fixation } \\
\text { with K-wires }\end{array}$ & 4 & 20 \\
\hline Closed Reduction, External fixation & 1 & 5 \\
\hline
\end{tabular}

Out of 20 patients, 15 (75\%) patients were treated with closed reduction and K-Wire fixation (Fig. 1A to F), 4 (20\%) patients with closed reduction and external fixation with Kwires (Fig. 2A - F) and 1 (5\%) patient with closed reduction and external fixation (Fig. 3A - F) (Table 6).

In the present study, 12 (60\%) patients had union within 2-3 months and 8 (40\%) patients had union in 3 - 4months (Table $5)$. There were no cases of delayed union or non-union. 


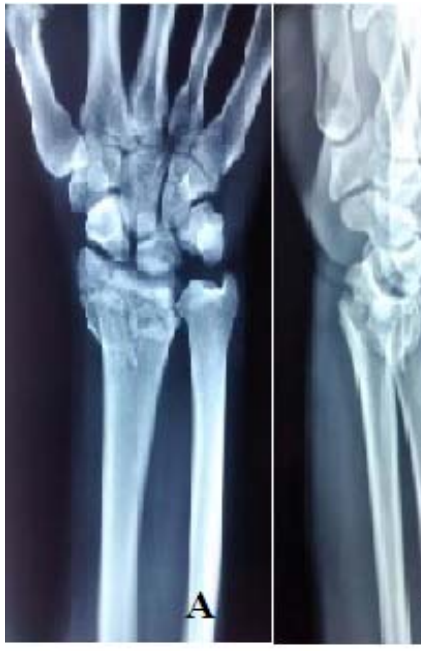

PRE-OPERATIVE

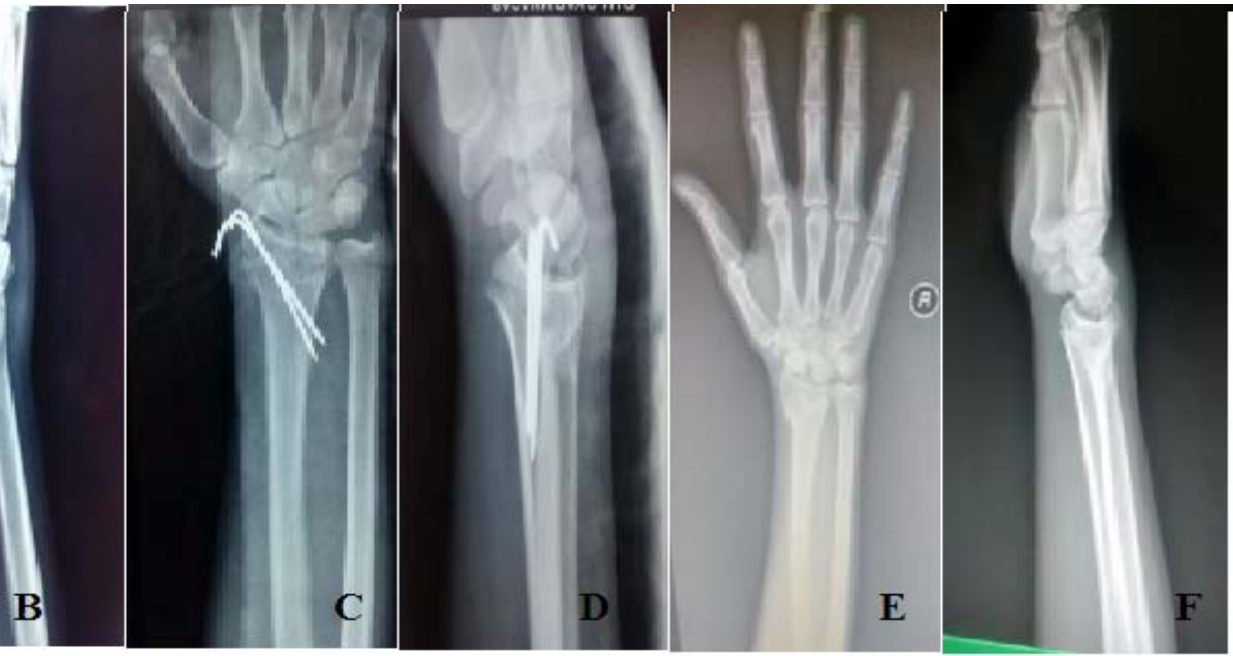

IMMEDLATE POST-OPERATIVE 12 WEEKS AFTER POST-OPERATIVE

Fig 1: Closed reduction with K-wire fixation: A, B- pre-operative, C, D- immediate post-operative, E, F- 12 weeks after post-operative

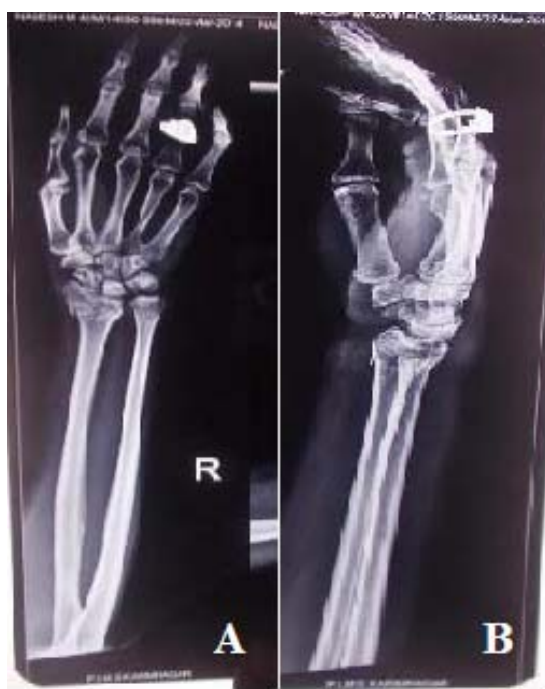

PRE-OPERATIVE
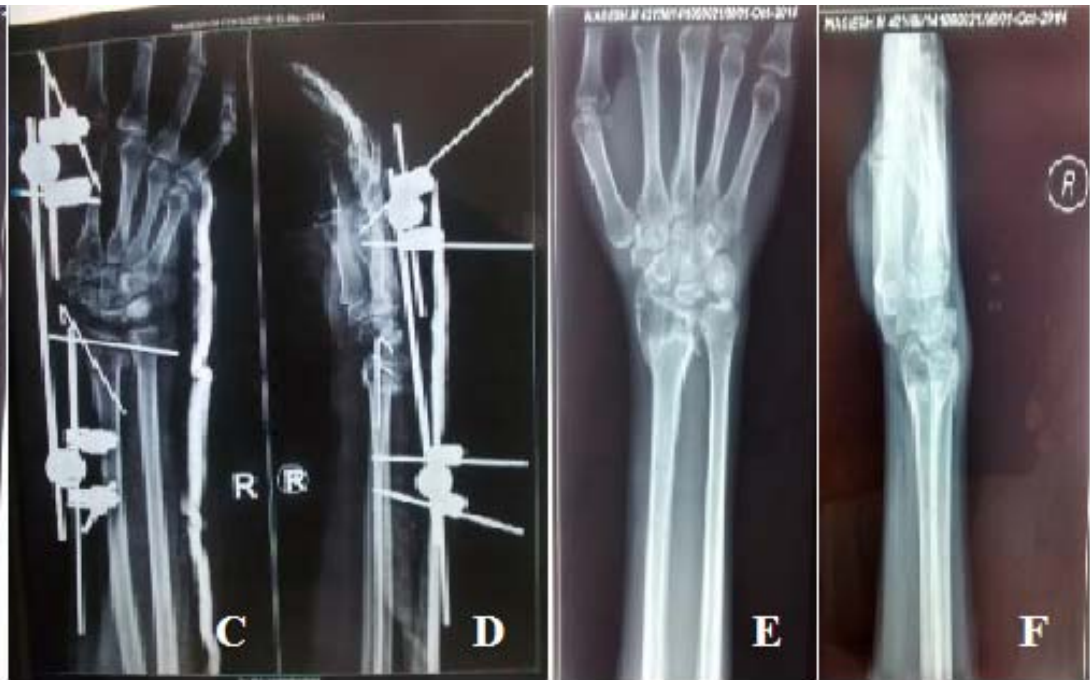

IMEEDIATE POST-OPERATIVE 28 WEEKS AFTER POST-OPERATIVE

Fig 2: Closed reduction external fixation with K-wire: A, B- pre-operative, C, D- immediate post-operative, E, F- 28 weeks after post-operative

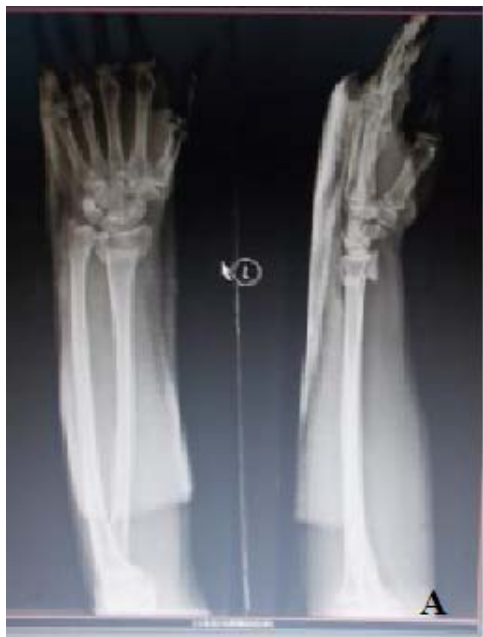

PRE-OPERATIVE

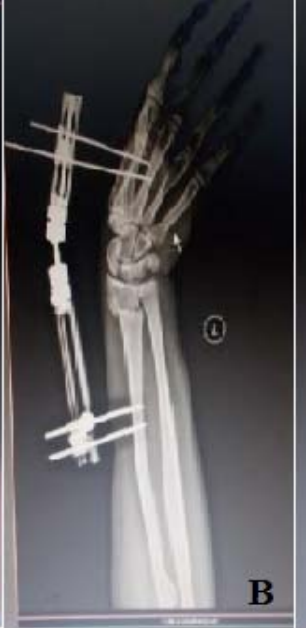

IMMIEDIATE POST-OPERATIVE

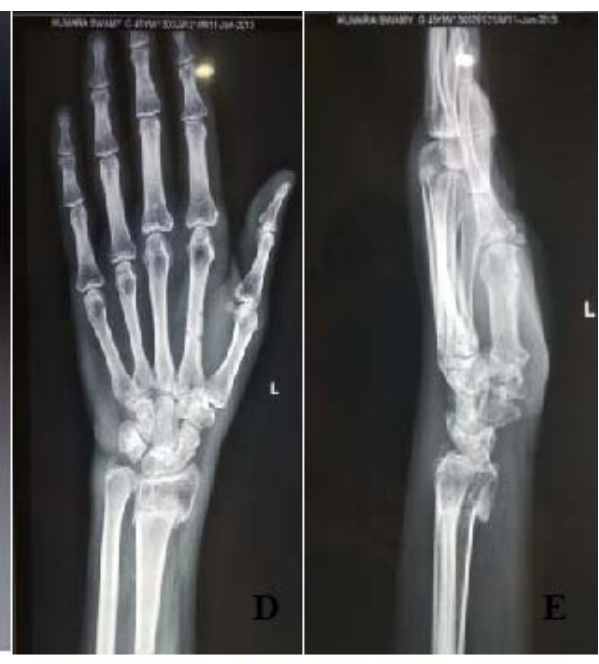

12 WEEKS AFTER POST-OPER

Fig 3: Closed reduction and external fixator: A- pre-operative, B, C- immediate post-operative, D, E- 12 weeks after post-operative 
Table 7: Deformity

\begin{tabular}{|c|c|c|c|c|}
\hline $\begin{array}{c}\text { Time of } \\
\text { Union }\end{array}$ & $\begin{array}{c}\text { Prominent } \\
\text { ulnar syloid }\end{array}$ & $\begin{array}{c}\text { Radial } \\
\text { deviation }\end{array}$ & $\begin{array}{c}\text { Dinner fork } \\
\text { deformity }\end{array}$ & Total \\
\hline $\begin{array}{c}\text { No. of } \\
\text { cases }\end{array}$ & 3 & 4 & 1 & 8 \\
\hline $\begin{array}{c}\text { Percentage } \\
(\%)\end{array}$ & 15 & 20 & 5 & 40 \\
\hline
\end{tabular}

Out of 20 patients, 8 (40\%) patients had residual deformity. 3 (15\%) patients had a prominent ulnar styloid, 4 (20\%) had radial deviation and 1 (5\%) had dinner fork deformity (Table 7). The deformities are more common in patients treated with K-wire fixation and external fixation with or without percutaneous pinning compared to open reduction and internal fixation with volar plating.

Table 8: Range of motion

\begin{tabular}{|c|c|c|}
\hline $\begin{array}{l}\text { Movement (within normal } \\
\text { functional range) }\end{array}$ & $\begin{array}{l}\text { No. of } \\
\text { cases }\end{array}$ & $\begin{array}{c}\text { Percentage } \\
(\%)\end{array}$ \\
\hline Dorsiflexion (min. $\left.45^{\circ}\right)$ & 16 & 80 \\
\hline Palmar flexion (min. $\left.30^{\circ}\right)$ & 17 & 85 \\
\hline Pronation (min. $50^{\circ}$ ) & 16 & 80 \\
\hline Supination (min. 50) & 18 & 90 \\
\hline Radial deviation (min. $15^{\circ}$ ) & 12 & 60 \\
\hline Ulnar deviation $\left(\min .15^{\circ}\right)$ & - & - \\
\hline Pain in distal radioulnar joint & 5 & 25 \\
\hline $\begin{array}{l}\text { Grip strength }\left(60^{\circ} \text { or less than on }\right. \\
\text { opposite side) }\end{array}$ & 1 & 5 \\
\hline
\end{tabular}

min. - minimum

In our study, $16(80 \%)$ patients had dorsiflexion movement within the normal functional range (minimum $45^{\circ}$ ), 17 (85\%) had palmar flexion $\left(30^{\circ}\right), 16(80 \%)$ had pronation $\left(50^{\circ}\right), 18$ (90\%) had supination $\left(50^{\circ}\right), 12(60 \%)$ had radial deviation $\left(15^{\circ}\right)$, and all patients had ulnar deviation $\left(15^{\circ}\right) .19$ (95\%) patients had grip strength more than $60 \%$ compared to the opposite side. 1 (5\%) had significant loss of grip strength (< $60 \%$ compared to the opposite side). 5 (25\%) patients had pain in the distal radioulnar joint (Table 8). None patients had stiffness of the wrist.

Table 9: Complications

\begin{tabular}{|c|c|c|c|c|}
\hline Complications & $\begin{array}{c}\text { Superficial } \\
\text { infection }\end{array}$ & $\begin{array}{c}\text { Pin tract } \\
\text { infection }\end{array}$ & $\begin{array}{c}\text { Mal- } \\
\text { union }\end{array}$ & Total \\
\hline No. of cases & 1 & 2 & 2 & 5 \\
\hline Percentage (\%) & 5 & 10 & 10 & 25 \\
\hline
\end{tabular}

1(5\%) patient who was treated with closed reduction K-wire fixation and external fixation had superficial wound infection, 2 (10\%) patients treated with closed reduction and K-wire fixation had pin tract infection. 2 (10\%) patients with closed reduction and K-wire fixation had significant mal-union (Table 9). None of the patients had median nerve complications or arthritic changes as described by Knirk and Jupiter ${ }^{[4]}$. There were no intra-operative complications.

The assessment of results was made using the demerit score system of Gartland and Werley ${ }^{[5]}$.

Table 10: Evaluation of functional outcome results

\begin{tabular}{|c|c|c|c|c|}
\hline Results & Excellent & Good & Fair & Poor \\
\hline No. of cases & 4 & 12 & 3 & 1 \\
\hline Percentage (\%) & 20 & 60 & 15 & 5 \\
\hline
\end{tabular}

In this study the functional outcome evaluated using the demerit score system we achieved excellent results in 4 (20\%) cases, good results in 12 (60\%), fair results in 3 (15\%) and poor result in 1 (5\%) case (Table 10).

\section{Discussion}

Distal radius fractures are extremely common injuries and tend to occur in a bimodal age distribution and it is remarkable that it remains one of the most challenging fractures to treat. Numerous studies have shown that extraarticular fractures as well as impacted stable fractures with minimal shortening can be managed conservatively. However, more often than not, distal radius fractures involve the radio carpal joint and / or the distal radioulnar joint. These require an anatomical reduction of the joint surface to reduce the incidence of post-traumatic arthritis and to guarantee a successful treatment outcome. The operative method selected to achieve the treatment objectives requires a careful study of the individual fracture pattern, level of activity, quality of bone and general medical condition. Recognition of fracture patterns, screw fixation of fractures and maintenance of reduction is the key for successful management of more complex fractures of distal radius.

The present study was undertaken to assess the functional outcome of surgical management of distal radial fractures using techniques such as closed reduction and K-wire fixation and external fixation with or without K-wire augmentation. The results were evaluated and compared with those obtained by various other studies utilizing different modalities of treatment.

In present study, distal radial fracture was more common in the $4^{\text {th }}$ and $5^{\text {th }}$ decade with an average of 40.66 years similar to the earlier findings ${ }^{[6,7]}$. In this study, results showed male predominance comparable to earlier reports [6-9]. High incidence of injuries in males may probably be due to their involvement in outdoor activities and heavy manual labour and also may be due to high energy injuries in male and low energy injuries in females.

Right side (dominant wrist) was more involved (80\%) than left side with $20 \%$ of the cases in our study comparable to the earlier findings ${ }^{[6,8,10-12]}$.

John k. Brad way et al. ${ }^{[7]}$ study results had equal involvement of both wrists and Louis Catalano III et al. ${ }^{[9]}$ results found increased involvement of the left wrist in their series contradictory to our results. More common right side involvement may be because of more number of right handed persons using their right hand first for protecting themselves while fall on the ground.

This study showed road traffic accident (RTA) as the most common mode of injury. 14 (70\%) cases had RTA and 6 (30\%) cases had fall on the out stretched hand. Harish Kapoor et al. ${ }^{[8]}$ also reported similar findings in their series. RTA are more common in the Indian subcontinent may be due to disobeying traffic rules, road conditions, vehicle's condition, driving under influence of alcohol, fast careless driving, inflation and increase in number of vehicles, increased per capital income. However, John K. Brad way et al. ${ }^{[7]}$ and Louis Catalano III et al. ${ }^{[9]}$ reported fall on the outstretched hand as the most common mode of injury contrary to our findings.

Based on Frykman's classification, present study had 4 (20\%) patients had Frykman's Type III, 2 (10\%) patients each of Type V and VI fractures, 12 (60\%) patients of Type VII fractures. The present study results are comparable to the reports of Pattanashetty et al. ${ }^{[6]}$, Harish kapoor et al. ${ }^{[8]}$ which may be due to the reason that the study was done in the same region and had similar findings for age and sex incidence, 
wrist involved and mode of injury.

In present study, 15 (75\%) patients were treated with closed reduction and K-wire fixation, 4 (20\%) with external fixation with percutaneous K-wire augmentation and 1 (5\%) with external fixator. But the series of Harish Kapoor et al. ${ }^{[8]}$ had almost equal distribution of cases that underwent closed reduction and external fixation and open reduction and internal fixation.

The present study encountered a complication rate of $25 \%$, out of which $10 \%$ was due to pin tract infection and $5 \%$ due to superficial wound infection. The incidence of mal-union was $10 \%$ with cases of nonunion, arthritis or nerve related complications.

One Patient treated with closed reduction and external fixation with K-wire had superficial infection treated with appropriate antibiotics and regular sterile dressings. 2 patients treated with K-wire had pin tract infection which was also controlled with appropriate antibiotics and sterile dressings, one patient had mal-union may be due to delayed for surgery, noncompliant patient, lack off regular follow up, physiotherapy. Pin tract infections can be prevented by subcutaneous incorporation of K-wire, appropriate time of removal necessary usually 4-6weeks, regular sterile dressings. John K. Bradway et al. ${ }^{[7]}$ reported a complication rate of $30 \%$ similar to the present series findings.

In present series we had $20 \%$ excellent, $60 \%$ good, $15 \%$ fair and $5 \%$ poor results. Patients, who obtained excellent results, had no residual deformities or pain. Range of motion was within the normal functional range. They had no arthritic changes or other complications. Radial length, volar tilt and articular step-off were within acceptable limits. Patients with good results had minimal residual deformities, pain and slight limitations. Results of our findings are within acceptable parameters.

Patients with fair results along with residual deformity, pain and limitation also had pain in the distal radio-ulnar joint and minimal complications. One patient who had poor result was operated on the $10^{\text {th }}$ day after injury as she had hypertension and Diabetes mellitus, associated trochanteric fracture and anaemia. After controlling hypertension, blood sugar levels with physician advice and treatment, anaemic status improvement with blood transfusions were treated with closed reduction and K-wire fixation for distal radius, dynamic hip screw fixation for trochanteric fracture.

The patient had residual dinner fork deformity, pain, limitation, disability and weakness. Most of her movements were not within the range required for normal function. She was non-compliant with regard to post-operative physiotherapy. She also had mal-union due to radial shortening.

Table 11: Functional outcome results in percentages (\%)

\begin{tabular}{|c|c|c|c|c|}
\hline \multirow{2}{*}{ Series } & \multicolumn{4}{|c|}{ Gartland and Werley scoring } \\
& \multicolumn{4}{|c|}{ system } \\
\cline { 2 - 5 } & Excellent & Good & Fair & Poor \\
\hline John K. Bradway et al (1989) ${ }^{[7]}$ & 56 & 25 & 19 & 0 \\
\hline PattanaShetty et al (2013) ${ }^{[6]}$ & 18.75 & 46.88 & 18.72 & 15.65 \\
\hline Present study & 20 & 60 & 15 & 5 \\
\hline
\end{tabular}

The present study functional assessment results are comparable to those of Pattanashetty et al. ${ }^{[6]}$ who had high percentage of good results and low percentage of fair and poor results (Table 11).

Closed reduction with subsequent intramedullary K-wire fixation (CRIF) produced good functional result in long term. With low rate of complication in closed reduction with K- wire under image intensifier can be recommended for stabilization of metacarpal fracture and implant removal at outpatient department is the further advantage. Further, fractures treated with CRIF with K-wire show faster union, faster recovery of daily activities and lesser stiffness compared

\section{Conclusions}

The study comprising of 20 cases of distal radial fractures in adult with different modalities of treatment like closed reduction with $\mathrm{K}$-wires fixation, external fixation with or without percutaneous k-wire augmentation was undertaken to assess the functional outcome of the results.

Surgical management of distal radial fractures, regardless of the type of fixation, produced excellent to good results with proper pre-operative evaluation, selection of the method based on fracture pattern, reducibility, stability and quality of bone, early fixation, proper wound and pin site care, early postoperative rehabilitation and patient education.

Union is not problem as these fractures occur in the metaphyseal region. But mal-union should be avoided by proper selection of implant and procedure, early reduction and fixation, better surgical skills.

\section{References}

1. Singer BR, McLauchlan GJ, Robinson CM. Epidemiology of fractures in 15,000 adults: the influence of age and gender J. Bone Joint Surg Br. 1998; 80:243 -248.

2. Owen RA, Melton LJ. 3rd, Johnson KA, et al. Incidence of Colles' fracture in a North American community. Am J Public Health 1982; 72(6):605-607.

3. Larsen CF, Lauritsen J. Epidemiology of acute wrist trauma. Int. J Epidemiol. 1993; 22:911-916.

4. Knirk JL, Jupiter JB. Intra-articular fractures of the distal end of the radius in young adults $\mathrm{J}$ Bone Joint Surg Am 1986; 68(5):647-659.

5. Gartland JJ, Werley CW. Evaluation of healed Colles' fractures. J Bone Joint Surg Am. 1951; 33(4):895-907.

6. Pattanashetty OB, Shushrut Bhavi, Monish Bami, Deepesh Daultani, Yogesh Mapari. Outcome of fracture distal end of radius in adults treated by open reduction and internal fixation with buttress plate; Kerala $\mathrm{J}$ of Orthop. 2013; 26(2):87-92.

7. Bradway JK, Amadio PC, Cooney WP. III. Open reduction and internal fixation of displaced, Comminuted intra-articular fractures of the distal end of the radius. $\mathrm{J}$ Bone Joint Surg. 1989; 71-A(6):839-847.

8. Kapoor H, Agarwal A, Dhaon BK. Displaced intraarticular fractures of distal radius: a comparative evaluation of results following closed reduction, external fixation and open reduction and internal fixation $\mathrm{J}$. Injury. 2000; 31(2):75-79.

9. Catalano LW III, Cole RJ, Gelberman RH, Evanoff BA, Gilula LA, Borrelli J Jr. displaced intra-articular fractures of the distal aspect of the radius. J Bone Joint Surg. 1997; 79-A(9):1290-1302.

10. Fitoussi F, Chow SP. Treatment of displaced Intra articular fractures of the distal end of Radius with Plates. J Bone Joint Surg (A). 1997; 79-A(9):1303 - 1311.

11. Othman AY. Fixation of dorsally displaced distal radius fractures with volar plate J Trauma. 2009; 66:1416-1420.

12. Anakwe R, Khan L, Cook R, Mc Eachan J. Locked volar plating for complex distal radius fractures: Patient reported outcomes and satisfaction. J Orthop Surg Res. 2010; 5:51. 